\title{
Maritime field studies: methods for exploring seafarers' physical activity
}

\author{
Marcus Oldenburg, Hans-Joachim Jensen
}

Institute for Occupational and Maritime Medicine Hamburg (ZfAM), University Medical Centre Hamburg-Eppendorf (UKE), Germany

\begin{abstract}
In order to determine the health status of seafarers, questionnaires are frequently applied or medical/ /psychological examinations conducted ashore, for example, in the form of medical fitness examinations or simulator training. In such a survey design, the occupational influences and the individual reaction cannot be ascertained. However, these aspects are especially important in the maritime context as employees on board are often exposed to the typical shipping-related stressors in the workplace for many months, both during working hours and during leisure time. In particular, it is assumed that working on board requires a high level of physical effort. Therefore, an exploration of occupational stress and strain, particularly the assessment of the seafarers' physical activity, should preferably be carried out in a comprehensive and realistic way in a maritime field study, i.e. an on-the-job survey directly on board.
\end{abstract}

(Int Marit Health 2019; 70, 2: 95-99)

Key words: activity on board, daily report, energy expenditure, heart rate, voyage episodes

\section{INTRODUCTION}

In order to determine the health status of seafarers, questionnaires are frequently applied or medical/psychological examinations conducted ashore, for example, in the form of medical fitness examinations or simulator training $[1,2]$. In such a survey design, the occupational influences and the individual reaction cannot be ascertained. However, these aspects are especially important in the maritime context as employees on board are often exposed to the typical shipping-related stressors in the workplace for many months, both during working hours and during leisure time $[3,4]$. In particular, it is assumed that working on board requires a high level of physical effort [5]. Therefore, an exploration of occupational stress and strain, particularly the assessment of the seafarers' physical activity, should preferably be carried out in a comprehensive and realistic way in a maritime field study, i.e. an on-the-job survey directly on board.

\section{MATERIALS AND METHODS}

In the following Table 1 [6-9], three complementary instruments for measuring seafarers' activity on board and the resulting strain are presented. These instruments were tested holistically in a (blinded) maritime field study and the informative value of these three combined instruments will be demonstrated by means of three case reports.

\section{DAILY REPORT OF PHYSICAL ACTIVITY/VOYAGE EPISODE}

All seafarers were requested to keep an accurate daily report for 5 minutes without gaps. On a continuous timeline from 0:00 to 24:00 each day they were to mark which activity level applied to them. The following levels of activity were distinguished: working hours, free time and sleeping time.

In addition, the examiner was able to record, down to the minute, the voyage episode (stay in port, river or sea passage) in which the ship was located at a given time according to a ship's journal.

\section{ACTIVITY PROFILE/ENERGY EXPENDITURE}

The SenseWear ${ }^{\circledR}$ armband monitor is designed to quantify physical activity (lying or sleeping time, high physical activity) and to measure seafarers' energy expenditure as metabolic equivalent of task (MET). This monitor is a light- 
Table 1. Selected instruments for measuring seafarers' activity on board

\begin{tabular}{llll}
\hline Measuring instruments & Parameters & $\begin{array}{l}\text { Previous use in maritime } \\
\text { field studies }\end{array}$ & Remarks \\
\hline $\begin{array}{l}\text { Daily report of physical activity } \\
\text { related to voyage episodes }\end{array}$ & Anamnestic activity level & $\begin{array}{l}\text { Harma et al. [6] } \\
\text { Ferguson et al. [7] } \\
\text { Eriksen et al. [8] }\end{array}$ & $\begin{array}{l}\text { Each seafarer independently } \\
\text { noted down their own activity, } \\
\text { lying and sleeping times }\end{array}$ \\
$\begin{array}{l}\text { SenseWear armband monitor; } \\
\text { Fa. Bodymedia }\end{array}$ & $\begin{array}{l}\text { Activity monitoring; } \\
\text { energy expenditure }\end{array}$ & Gander et al. [9] & These devices do not restrict the \\
$\begin{array}{l}\text { Polar watch RS } 800 \text { Multi } \\
\text { (chest strap) }\end{array}$ & Heart rate/variability & & seafarers in their daily work
\end{tabular}

weight 82-gram device worn on the right upper arm above the triceps muscle. The attachment with an elastic strap provides a high level of comfort; there is no wiring. The monitor measures physiological parameters (2-axis accelerometry, heat flow, skin temperature and galvanic skin reaction (skin impedance) using four different sensors.

In maritime field studies, the physical activity, heart rate and energy expenditure of seafarers should be continuously measured over a minimum of 2 days. The armband monitor has already been tested and successfully used as an activity measuring system in numerous studies [10, 11]. This device has also been repeatedly used in occupational medicine $[12,13]$.

\section{HEART RATE (VARIABILITY)}

Measuring heart rate and heart rate variability as important parameters of the psychophysical strain on board is possible with the Polar watch RS 800 Multi. For this measurement, an elastic chest strap and a special wristwatch (transmitter and receiver) are worn over a period of at least 48 hours. The wearer is hardly hampered in his work routine as no wiring is involved.

It should be noted that artefacts in the derivation (possibly triggered by ship-related sources of interference) but also cardiac arrhythmia can lead to false measurements of the heart rate. Therefore, an artefact correction must be performed; heart rates $>200$ bpm and < 35 bpm can be interpreted as artefacts and should not be considered in the evaluation. Non-physiological heart rate sections ("hum frequency") are cut out.

The Polar watch has already been used in various studies [14-16].

\section{HOLISTIC ASSESSMENT OF SEAFARERS' PHYSICAL ACTIVITY}

In parallel measurements, 3 seafarers representing different shipboard groups wore the Polar watch simultaneously with the armband monitor for an uninterrupted period of at least 4 days. After merging the data in a spreadsheet programme, the continuously measured heart rate and the energy expenditure were holistically displayed and evaluated for each occupational group, taking into account the various voyage episodes (Port stay, River passage and Sea passage) and the activity level marked in the daily report. The wearing compliance, especially of the armband monitor, was excellent at over $92 \%$.

The holistic activity assessment of a nautical officer (assigned to a 4/8 watch system, i.e., alternating 4-hours watch and 8-hour-free shift), a deck rating and an engine room employee is illustrated in Figures 1-3. In these figures, the voyage episodes in the time stream from the beginning to the end of the parallel survey is shown in the lowest strip and differentiated by colour. The uppermost strip represents the activity phases (working hours, free time and sleeping time) noted in the daily report. The second, third and fourth upper strips correspond to the phases "sleeping time", "lying time" and "high physical activity" recorded by the armband monitor. The upper red curve shows the time-adapted heart rate measured by the Polar watch, and the green curve represents the METs assessed by means of the armband monitor. As expected, a parallel course of the heart rate and the METS is found during all noted activity levels in the following examples.

\section{EXAMPLES FOR THE HOLISTIC ACTIVITY ASSESSMENT ON BOARD}

\section{NAUTICAL OFFICER}

Figure 1 illustrates that the investigated nautical officer routinely followed a 4-hour watch shift during the sea passage (red bars in the daily report strip during phases of the sea passage marked "green" below in the voyage episodes strip "SP"). This period was followed by an approximately 8-hour-free shift (lime or dark green bars in the daily report strip). During the port stay ("PoS", green bar in the voyage episode strip below), the work assignment switched from a $4 / 8$ to a $6 / 6$ watch system with up to 7 hours of work and short interim breaks.

Overall, this holistic activity assessment reveals how irregular the working hours for the nautical officer were, primarily in the port and adapted to the respective voyage episodes. This illustrates exemplarily that a regular $4 / 8$ watch system for nautical officers is only partially feasible in practice. 


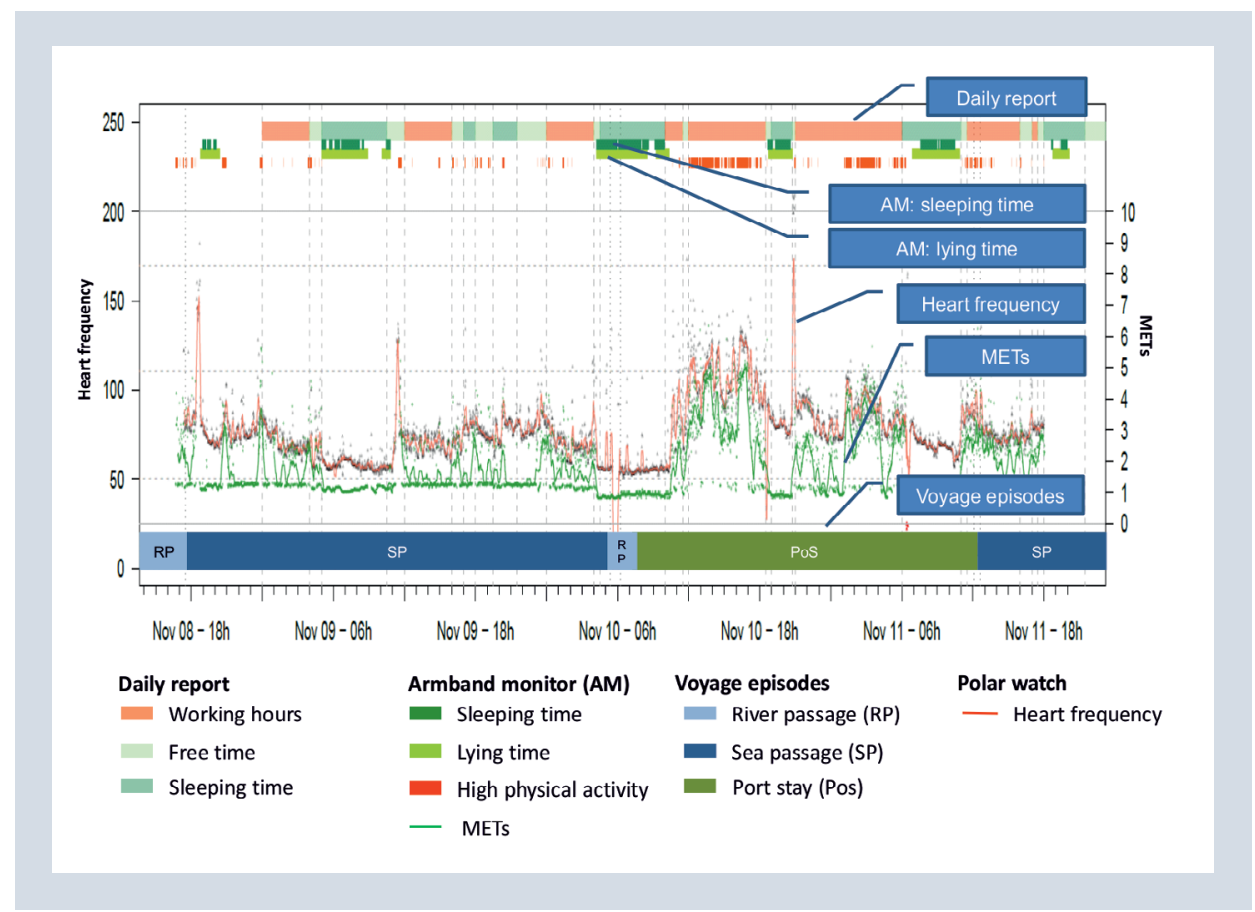

Figure 1. Holistic activity assessment of a nautical officer; MET - metabolic equivalent of task

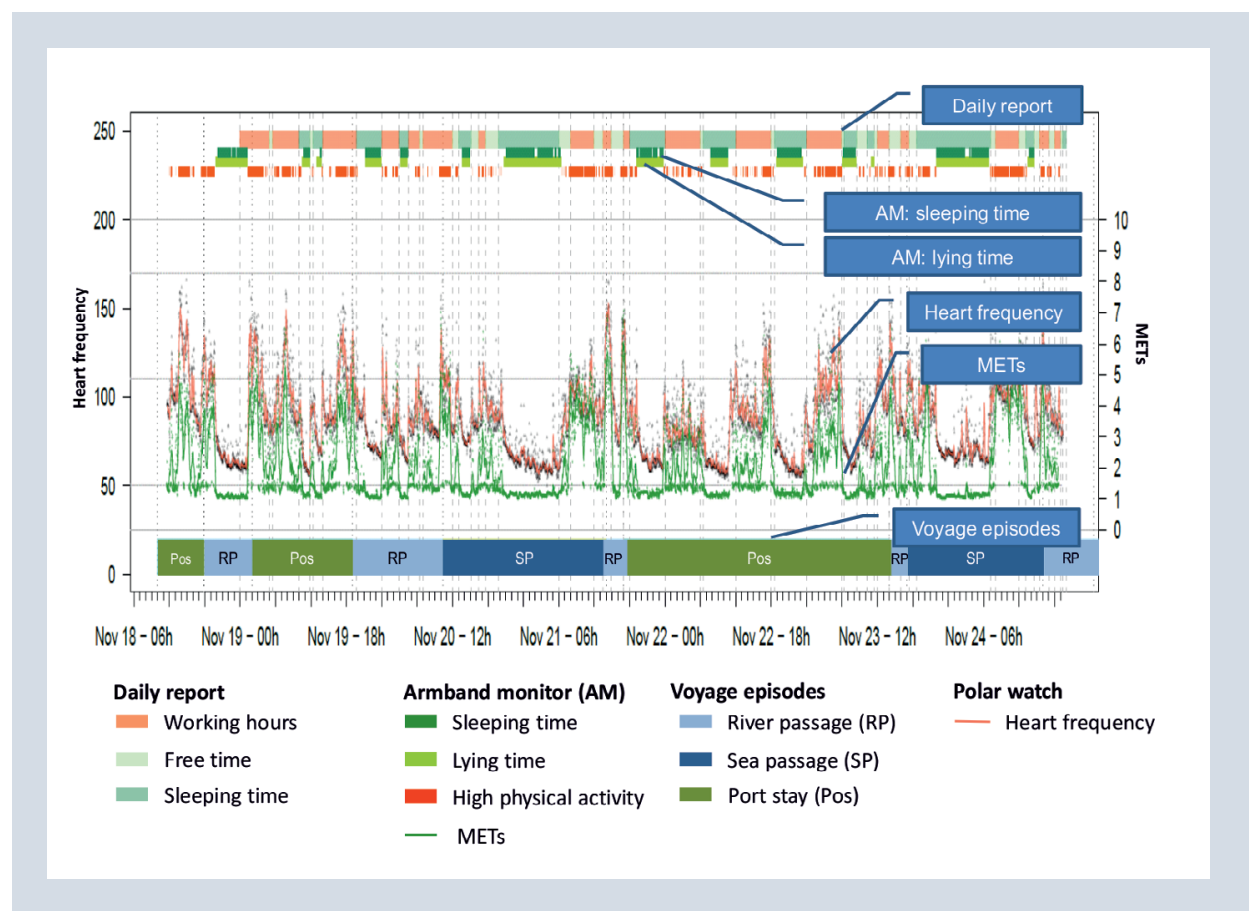

Figure 2. Holistic activity assessment of a deck rating; MET - metabolic equivalent of task

\section{DECK RATING}

During the labour-intensive voyage episodes of port stay and river passage, the observed deck rating's work routine was characterised by numerous episodes with sev- eral working hours and only short breaks (Fig. 2). During the work phases, repeated heart rate spikes of up to $150 \mathrm{bpm}$ were noted, indicating an increased physical effort. The investigation on board by the examiners revealed 


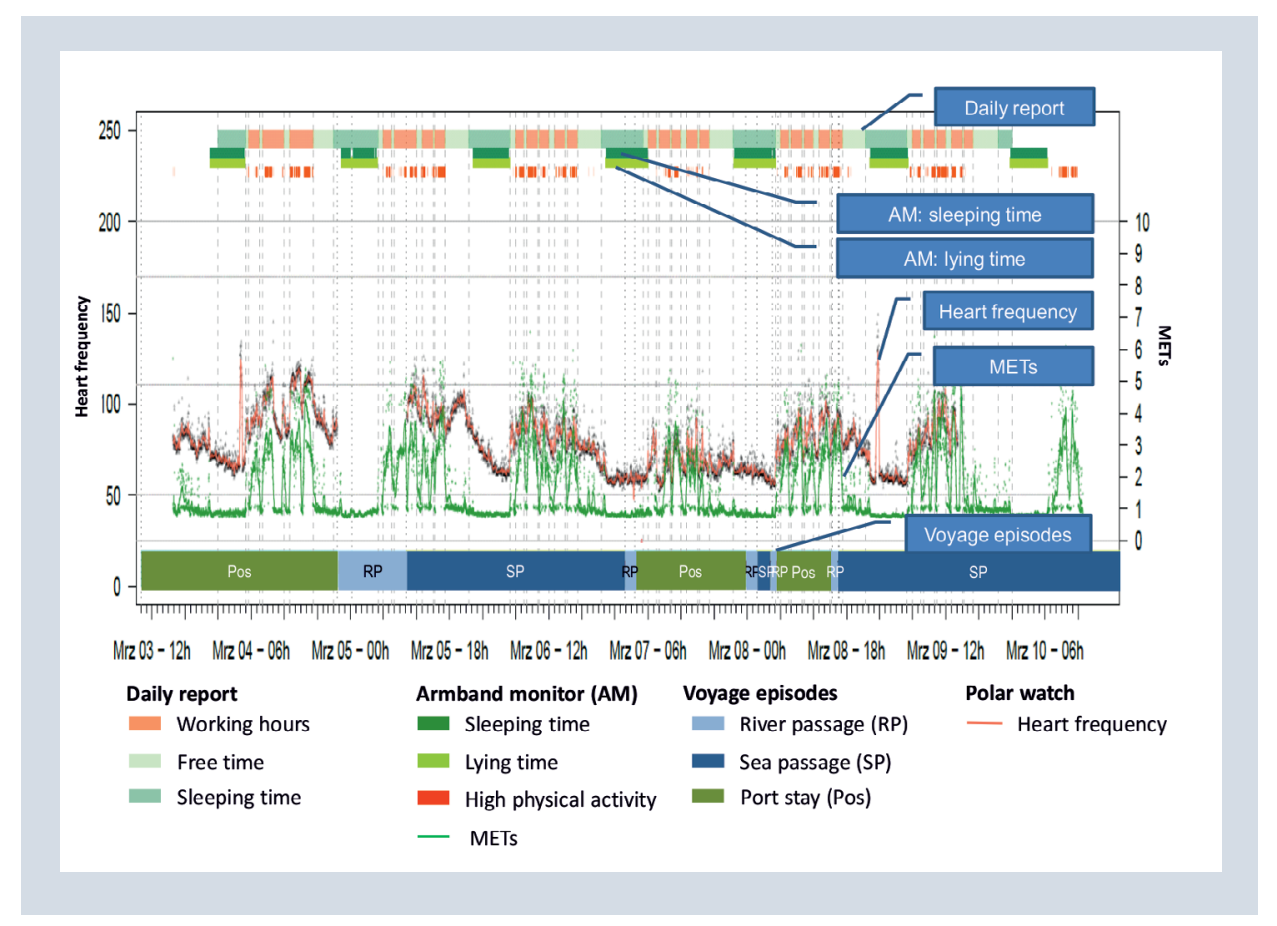

Figure 3. Holistic activity assessment of a crew member from the engine room; MET - metabolic equivalent of task

that the deck ratings had carried out extensive loading and unloading activities during port stay (in particular connecting and stabilising the containers with heavy iron bars; so-called "lashing"). At the same time as lashing was carried out, the heart rate peaked (red curve) and elevated METS (green curve) were observed, which means a high level of physical exertion. Thus, supplementary expert observations made it possible to assign biometric stress reactions to specific work-related situations. Furthermore, Figure 2 shows that the work intensification in the port was compensated during the sea passage by longer free time and sleeping episodes.

\section{ENGINE ROOM EMPLOYEE}

In contrast to the watch-keeping crew, the work schedule of the engine room personnel corresponded to a relatively constant day shift system, which was even practiced regardless of the voyage period, as shown in Figure 3.

\section{LIMITATIONS OF A MARITIME FIELD SURVEY}

A maritime field study has the following limitations that have to be considered in the evaluation of the results [4].

\section{FIELD SURVEY}

A scientific evaluation during the operation of a ship in the sense of a "field study on board" requires a lot of effort due to frequent crew changes, the limited duration of a study and the other uncontrollable variables in the maritime setting. Significant limitations in the evaluation of such a field study are:

- a small study sample (per container ship a maximum of 25 people);

- insufficient detection of long-term effects due to the cross-sectional design of the study on ships with ever-changing personnel on board;

- multinational crews with different socio-cultural backgrounds;

- multiple labour and environmental factors (e.g. shipping area, crew groups, voyage episodes, duty on board, swell); this results in confounding and non-controllability of synchronously influencing factors;

- difficulties of the multinational crew with language understanding.

\section{UNCLEAR REPRESENTATIVENESS \\ OF THE PARTICIPATING SHIPPING COMPANIES}

When recruiting the study sample, all shipping companies willing to participate should first be included in a study. However, it should be examined whether the selected shipping companies are representative of the respective survey population with regard to the crew structure and the underlying safety standards. In principle, it cannot be ruled out that shipping companies with worse working conditions on board do not participate in a study, which would result in a selection process. Although this cannot be verified by data, it is more likely to underestimate the workload and stress in the sample being studied. 


\section{SMALL SAMPLE SIZE}

Due to the elaborate study design of a maritime field study, it is often only possible to compile a relatively small study sample. This leads to the problem that a differentiated stratification of stress and strain is only partially possible, for example, for the various occupational groups on board.

\section{VALIDITY OF THE PHYSIOLOGICAL MEASUREMENT METHODS}

In general, the examiner should take into account that the physiological measurement methods in cross-sectional studies only record acute biometric responses. Long-term effects in terms of long-term demands can generally not be determined with these methods, since the measurement results are acutely influenced by occupational (and possibly also non-occupational) effects. The presence of the examiners on board and, in general, the investigation situation (for example, the use of a measuring instrument, regular saliva sampling) could also influence the stress on board. Therefore, care should be taken during the field study to ensure that the examination on board has the least possible effect on the crew's work routine (for example no wiring of subjects with heavy or motion-limiting measuring devices). In addition, many examinations should take place after several days of examiners' presence on board so that contact and a first basis of trust can be established with the crew.

Despite the limitations mentioned above, maritime field studies are indispensable for estimating the need for preventive measures in merchant shipping, since only concrete and up-to-date measurements on board can reveal and objectify burdens in ship operation. The recording of the physiological response to a shipboard stressor, i.e. the strain of the ship's crew, also remains reserved for the methodical approach of an investigation on board. Surveys ashore, for instance, ship simulator trainings, are not suitable for exploring the ship crews' workload, which typically lasts several months on board, and its long-term effects.

\section{ACKNOWLEDGEMENTS}

This study was funded by the BG Verkehr, Hamburg, Germany.

\section{REFERENCES}

1. Main LC, Wolkow A, Chambers TP. Quantifying the Physiological Stress Response to Simulated Maritime Pilotage Tasks: The Influence of Task Complexity and Pilot Experience. J Occup Environ Med. 2017; 59(11): 1078-1083, doi: 10.1097/JOM.0000000000001161, indexed in Pubmed: 28922309.

2. Zevallos J, Hulshof CT, Mutsaerts T, et al. Outcomes of seafarer work fitness qualifications in the Netherlands. Occup Med (Lond).
2014; 64(4): 267-270, doi: 10.1093/occmed/kqu020, indexed in Pubmed: 24604102.

3. Oldenburg M, Jensen HJ, Latza U, et al. Seafaring stressors aboard merchant and passenger ships. Int J Public Health. 2009; 54(2): 96-105, doi: 10.1007/s00038-009-7067-z, indexed in Pubmed: 19288290.

4. Oldenburg M, Hogan B, Jensen HJ. Systematic review of maritime field studies about stress and strain in seafaring. Int Arch Occup Environ Health. 2013; 86(1): 1-15, doi: 10.1007/s00420-0120801-5, indexed in Pubmed: 22915144.

5. Oldenburg M, Baur X, Schlaich C, et al. Seafaring stressors aboard merchant and passenger ships. Int J Public Health. 2009; 54(2): 96-105, doi: 10.1007/s00038-009-7067-z, indexed in Pubmed: 19288290

6. Härmä M, Partinen M, Repo R, et al. Effects of $6 / 6$ and $4 / 8$ watch systems on sleepiness among bridge officers. Chronobiol Int. 2008; 25(2): 413-423, doi: 10.1080/07420520802106769, indexed in Pubmed: 18484371.

7. Ferguson SA, Lamond N, Kandelaars K, et al. The impact of short, irregular sleep opportunities at sea on the alertness of marine pilots working extended hours. Chronobiol Int. 2008; 25(2): 399-411, doi: 10.1080/07420520802106819, indexed in Pubmed: 18484370.

8. Eriksen CA, Gillberg M, Vestergren P. Sleepiness and sleep in a simulated "six hours on/six hours off" sea watch system. Chronobiol Int. 2006; 23(6): 1193-1202, doi: 10.1080/07420520601057981, indexed in Pubmed: 17190705.

9. Gander P, van den Berg M, Signal L. Sleep and sleepiness of fishermen on rotating schedules. Chronobiol Int. 2008; 25(2): 389-398, indexed in Pubmed: 18533331.

10. Pitta F, Troosters T, Probst VS, et al. Quantifying physical activity in daily life with questionnaires and motion sensors in COPD. Eur Respir J. 2006; 27(5): 1040-1055, doi: 10.1183/09031936.06.00064105, indexed in Pubmed: 16707399.

11. King GA, Torres N, Potter C, et al. Comparison of activity monitors to estimate energy cost of treadmill exercise. Med Sci Sports Exerc. 2004; 36(7): 1244-1251, indexed in Pubmed: 15235333.

12. Manfredini F, Borleri D, Mosconi G. [Measurement of energy expenditure in a group of construction workers during work]. $G$ Ital Med Lav Ergon. 2007; 29(3 Suppl): 722-725, indexed in Pubmed: 18409925.

13. Sharkey PF, Danoff JR, Klein GR, et al. Surgeon energy expenditure during total joint arthroplasty. J Arthroplasty. 2007; 22(2): 210-212, doi: 10.1016/j.arth.2006.08.002, indexed in Pubmed: 17275635.

14. Radespiel-Tröger M, Rauh R, Mahlke C, et al. Agreement of two different methods for measurement of heart rate variability. Clin Auton Res. 2003; 13(2): 99-102, doi: 10.1007/s10286-003-0085-7, indexed in Pubmed: 12720094.

15. Löllgen D, Jung K, Mück-Weymann M. Herzratenvariabilität (HRV) im Sport? Methodische Überlegungen zur vergleichenden Messung mittels Polar S 810 und Standardmethoden der Medizin. In: Hottenrott $\mathrm{K}$, editor. Herzfrequenzvariabilität im Fitness- und Gesundheitssport Schriften der Deutschen Vereinigung für Sportwissenschaft. Hamburg Czwalina Verlag. ; 2003: 121-135.

16. Gamelin FX, Berthoin S, Bosquet L. Validity of the polar S810 heart rate monitor to measure R-R intervals at rest. Med Sci Sports Exerc. 2006; 38(5): 887-893, doi: 10.1249/01. mss.0000218135.79476.9c, indexed in Pubmed: 16672842. 